SUBJECT AREAS:

BIOMATERIALS - CELLS

BIOMIMETICS

TISSUE ENGINEERING

Received

24 June 2014

Accepted

24 December 2014

Published

22 January 2015

Correspondence and requests for materials should be addressed to

A.W.F. (feinberg@ andrew.cmu.edu)

\section{In Vitro Expansion of Corneal Endothelial Cells on Biomimetic Substrates}

\author{
Rachelle N. Palchesko ${ }^{1,2,3}$, Kira L. Lathrop ${ }^{2,3}$, James L. Funderburgh ${ }^{2,3}$ \& Adam W. Feinberg ${ }^{1,4}$
}

'Department of Biomedical Engineering, Carnegie Mellon University, Pittsburgh, PA 15213, ${ }^{2}$ Department of Ophthalmology, University of Pittsburgh, Pittsburgh PA, 15213, ${ }^{3}$ Louis J. Fox Center for Vision Restoration, Pittsburgh PA 15213, ${ }^{4}$ Department of Materials Science and Engineering, Carnegie Mellon University, Pittsburgh PA 15213.

Corneal endothelial (CE) cells do not divide in vivo, leading to edema, corneal clouding and vision loss when the density drops below a critical level. The endothelium can be replaced by transplanting allogeneic tissue; however, access to donated tissue is limited worldwide resulting in critical need for new sources of corneal grafts. In vitro expansion of CE cells is a potential solution, but is challenging due to limited proliferation and loss of phenotype in vitro via endothelial to mesenchymal transformation (EMT) and senescence. We hypothesized that a bioengineered substrate recapitulating chemo-mechanical properties of Descemet's membrane would improve the in vitro expansion of $\mathrm{CE}$ cells while maintaining phenotype. Results show that bovine $\mathrm{CE}$ cells cultured on a polydimethylsiloxane surface with elastic modulus of $50 \mathrm{kPa}$ and collagen IV coating achieved $>3000$-fold expansion. Cells grew in higher-density monolayers with polygonal morphology and ZO-1 localization at cell-cell junctions in contrast to control cells on polystyrene that lost these phenotypic markers coupled with increased $\alpha$-smooth muscle actin expression and fibronectin fibril assembly. In total, these results demonstrate that a biomimetic substrate presenting native basement membrane ECM proteins and mechanical environment may be a key element in bioengineering functional CE layers for potential therapeutic applications.

T he corneal endothelium (CE) forms a monolayer on the posterior surface of the cornea that actively pumps water from the corneal stroma into the aqueous humor ${ }^{1,2}$. At birth the human CE contains $\sim 5,000$ cells/ $\mathrm{mm}^{2}$, but the cells are mitotically inactive and as a result cell density decreases throughout life ${ }^{3,4}$. There is a rapid, non-linear decrease in cell density from the second trimester to ages $2-10$, most likely due to the increase in the size of the cornea, followed by a slower, linear decrease in cell density due to cell aging and death ${ }^{5,6}$. When $\mathrm{CE}$ damage, disease, or aging causes cell density to drop below $\sim 500 \mathrm{cells} / \mathrm{mm}^{2}$, the CE can no longer pump enough water to compensate for diffusion into the cornea, resulting in stromal edema, corneal clouding and eventual vision loss ${ }^{7}$. Transplantation of donor CE tissue, either as a full-thickness penetrating keratoplasty (PK) or as one of the several forms of endothelial keratoplasty, can restore CE function and corneal transparency ${ }^{8-11}$. While successful, rejection and recurrence of CE cell loss remain common complications of these whole tissue/organ grafts ${ }^{12-16}$. Further, these grafts require use of donated cadaveric tissue, which in many parts of the world is limited in availability or is entirely non-existent ${ }^{14,16}$. Thus, there remains a critical need for new therapies to repair, regenerate or replace the $\mathrm{CE}$ in order to reverse corneal edema and restore normal vision.

Currently, endothelial grafts constitute a 1:1 replacement of CE tissue with that of a cadaveric cornea. The number of such grafts produced by each donor eye could be increased significantly if CE cells were expanded in culture before grafting. Such an approach requires the ability to expand CE cells in a manner that maintains physiological $\mathrm{CE}$ function and a compatible carrier on which to transplant an engineered $\mathrm{CE}$ monolayer. Historically, cultured adult CE cells have been observed to undergo one or two population doublings in vitro, but rapidly become senescent or undergo endothelial to mesenchymal transition (EMT) to a fibroblastic phenotype $^{17-19}$. A number of studies have optimized culture media formulation ${ }^{15}$ and supplemented with growth factors such as FGF2, EGF and $\mathrm{NGF}^{1,20}$ to stimulate CEC growth. Additionally, the use of extracts from bovine corneal endothelial cells ${ }^{21}$,or small molecules such as Rho kinase inhibitor Y27632 ${ }^{22-24}$ and ascorbic acid 2 phosphate $e^{25,26}$ have been used to expand CE cells. Still other studies have investigated improving CE cell isolation ${ }^{27-31}$, using various extracellular matrix (ECM) proteins to improve $\mathrm{CE}$ cell attachment $\mathrm{t}^{27,32-34}$, and immortalizing the $\mathrm{CE}$ cells with the SV40 T-antigen ${ }^{30,31}$. All of these approaches have resulted in some measurable improvement in CE cell expansion in vitro, but none have achieved satisfactory results. Reproducibility, senescence, and EMT after expansion in vitro continue to pose significant barriers to generating enough $\mathrm{CE}$ cells for therapeutic applications. 
Here we have focused on the microenvironment of the CE cells, specifically the chemical and mechanical properties, as a means to increase proliferation and maintain phenotype. Researchers have shown that interaction with the ECM controls cell cycle entry, differentiation, and function for a variety cell types ${ }^{35-38}$. These cellmatrix interactions largely result from integrin binding to specific amino acid motifs in the ECM proteins, and the signaling resulting from them is strongly influenced by the mechanical and topological properties of the matrix ${ }^{35-38}$. In the current study we hypothesized that expansion of CE cells in a manner that maintains phenotype is dependent on the mechanical and biochemical properties of the substrate. To test this we first screened a range of substrate elastic moduli and ECM protein coatings spanning from the standard tissue culture-treated polystyrene (TCPS) to softer substrates similar to Descemet's membrane to ultra-soft substrates. Bovine CE cells were used because we could obtain $25-50$ age matched $1-2$ year-old eyes at one time to get the number of cells required for large screening studies, which was not possible using human tissue. After identifying a substrate that best preserved CE phenotype, we then evaluated the ability of this substrate to also improve in vitro expansion. The results presented here will demonstrate that engineering a biomimetic substrate with mechanical and ECM properties similar to Descemet's membrane provides a microenvironment that promotes both the expansion and normal phenotype of bovine CE cells during extended in vitro culture. This is important, because it shows the ability to use physical and insoluble chemical cues to expand bovine CE cells, which could provide a potential pathway for generating large numbers of human CE cells for future therapeutic applications.

\section{Results}

CE Cells Cultured on a Rigid Substrate Acquire an Abnormal Morphology. Cells in a native CE layer exhibit a distinctive morphology consisting of regular, hexagonal cells densely packed in a continuous monolayer ${ }^{20,39-41}$. This morphology is common across species, including that of the bovine corneas used in this study (Fig. 1a). The tight junction protein zona occludens 1 (ZO1) formed a near-continuous band at cell-cell junctions and immediately interior to the ZO-1 staining, F-actin was organized into a thin cortical layer. No actin stress fibers were observed to traverse the cell bodies. In contrast, CE cells grown on standard cell culture surfaces such as glass coverslips (Fig. 1b) or TCPS (Fig. 1c) were characterized by lower cell density, irregular morphology, punctate and discontinuous $\mathrm{ZO}-1$ at the cell-cell borders and F-actin organized into a much thicker cortical cytoskeleton that extended many micrometers in from the cell border. This aberrant CE morphology was observed from the first passage of $\mathrm{CE}$ cells on rigid surfaces, and became more pronounced through successive passages. Using the CE morphology as a metric, our goal was to engineer a substrate that supported CE growth and monolayer formation such that the morphology of the cells more closely resembled that observed in the intact endothelium.

Screening of Substrate Biochemical and Mechanical Properties to Determine the Effect on CE Morphology. We hypothesized that matching the mechanical and biochemical properties of the native Descemet's membrane would aid in maintaining a differentiated phenotype of cultured CE cells. This was tested using a 36condition screen to systematically vary substrate elastic modulus and ECM protein surface coating. To do this we used a tunable polydimethylsiloxane (PDMS) elastomer system to engineer substrates with six different elastic moduli $(5,50,130,830,1340$ or $1720 \mathrm{kPa})^{42}$ that were used as-is or were coated with the ECM proteins fibronectin, laminin 111, collagen type I, collagen type IV, or a blend of laminin and collagen type IV (see Supplementary Fig. S1 online). Each substrate condition was seeded with passage 2 (P2) bovine CE cells that had been expanded from isolation on TCPS.
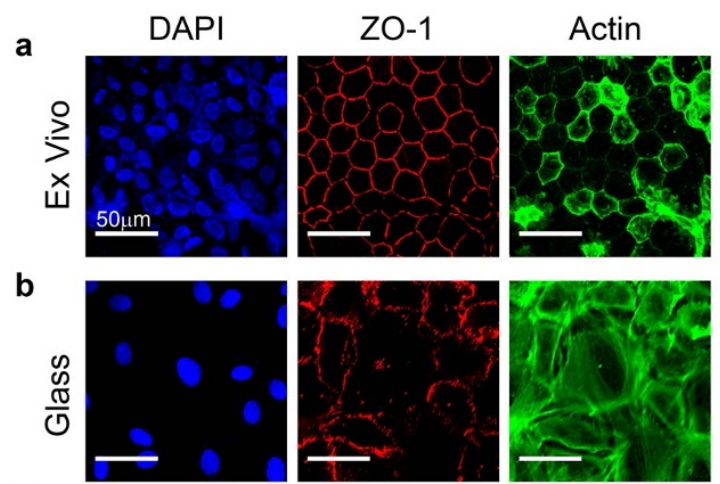

C
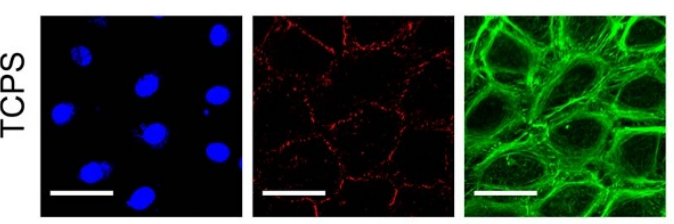

Figure $1 \mid$ CE cells lose differentiated morphology when cultured on glass or tissue culture polystyrene. (a) Example of ex vivo, intact endothelium from the bovine cornea where cells exhibit a polygonal, mostly hexagonal shape and small size with the tight junction protein $\mathrm{ZO}-1$ (red) present at cell borders and F-actin (green) located cortically. (b) CE cells cultured for one passage on a rigid glass substrate have reduced $\mathrm{ZO}-1$ localization at the cell-cell borders and F-actin fibers present cortically as well as throughout the cell body. (c) CE cells cultured on TCPS for one passage appear similar to CE cells on glass, showing a loss of phenotypic shape and ZO-1 and F-actin localization relative to the ex vivo tissue. Cells are stained for nuclei (blue), tight junction protein $\mathrm{ZO}-1$ (red) and F-actin (green) and scale bars are $50 \mu \mathrm{m}$.

As shown in Fig. 2, representative images stained for F-actin and ZO1 revealed marked differences as a function of substrate properties after 7 days in culture. Cell-density was similar on the various substrates, but on the stiffer PDMS formulations $(E \geq 830 \mathrm{kPa})$, F-actin was most often observed in a thick cortical cytoskeleton with internal stress fibers and minimal ZO-1 present at the cell-cell junctions. The exception to this was on substrates coated with collagen IV, all of which exhibited similar polygonal morphology, ZO-1 at cell borders, and F-actin located cortically. Substrates with lower elastic moduli induced variable cell morphologies depending on the protein coating. For example, fibronectin and collagen I coated surfaces showed poor CE phenotype for all of elastic modulus, again with with reduced $\mathrm{ZO}-1$ and non-cortical F-actin fibers. In contrast, laminin and laminin/collagen IV surfaces showed a general decrease in non-cortical F-actin fibers and increase in ZO-1 at the cell borders as elastic modulus decreased from $1.7 \mathrm{MPa}$ to $50 \mathrm{kPa}$. Unexpectedly, CE cells on the softest substrate $(E=5 \mathrm{kPa})$, appeared similar to stiffer substrates, demonstrating that the substrate could be too soft to support the desired morphology. Finally, CE cells on uncoated PDMS (i.e., coated only with ECM proteins adsorbed from the FBS in the media) did exhibit an in vivo-like morphology in some conditions, but the cells divided very slowly, taking a long time to reach confluence. After a qualitative analysis of all 36 conditions, we determined that the best phenotypic expression of continuous $\mathrm{ZO}$ 1 at the cell-cell border and a thin, cortical F-actin cytoskeleton occurred for CE cells on the PDMS with the collagen type IV protein coating and an elastic modulus of $50 \mathrm{kPa}$, which we termed $\mathrm{PDMS}_{50+\mathrm{COL} 4}$. Because this is similar to the reported composition and elastic modulus of Descemet's membrane, we also referred to this specific $\mathrm{PDMS}_{50+\mathrm{COL} 4}$ substrate as biomimetic ${ }^{8,43,44}$.

Enhancement of CE Cell Proliferation on the Biomimetic PDMS Substrate. Next, we asked whether the $\mathrm{PDMS}_{50+\mathrm{COL} 4}$ biomimetic 

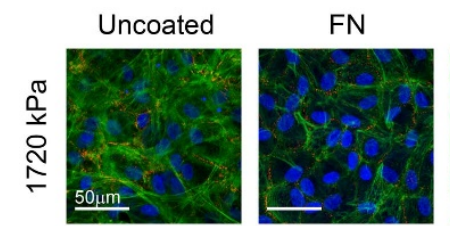

COL1
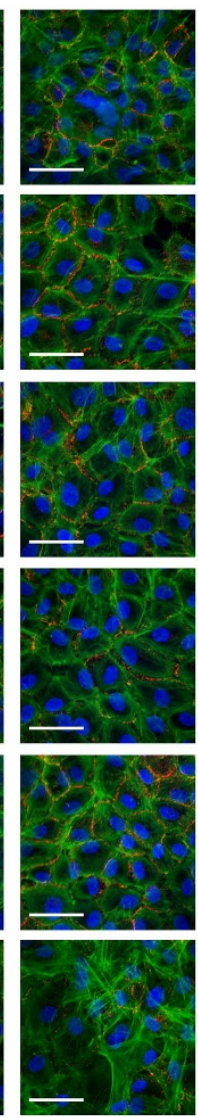

LAM
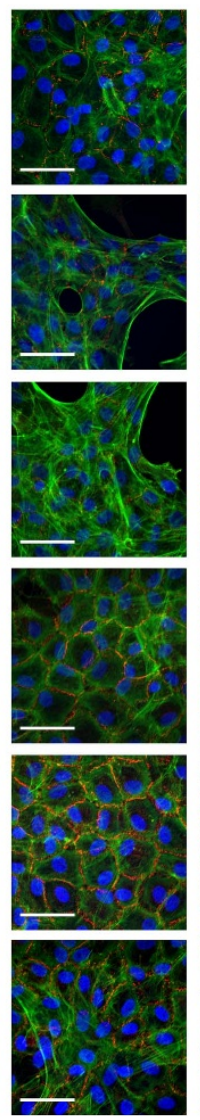

COL4
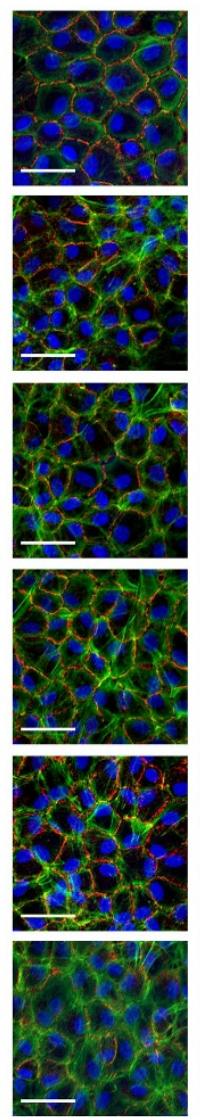

$\mathrm{LAM}+\mathrm{COL} 4$
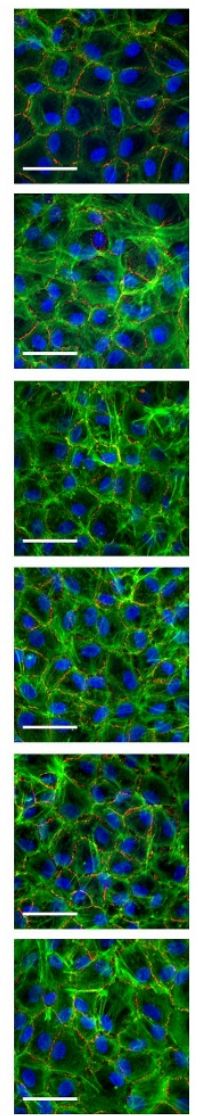

Figure $2 \mid$ Screening the response of CE cells to variable substrate elastic modulus and ECM protein coating. CE cells were cultured on one of 36 different PDMS substrates with elastic modulus of 5, 50, 130, 830, 1340 or $1720 \mathrm{kPa}$ and uncoated or coated with the ECM proteins fibronectin (FN), collagen type I (COLI), laminin (LAM), collagen type IV (COL4) or LAM and COL4. Representative fluorescent images show CE cells stained for nuclei (blue), ZO-1 (red) and F-actin (green), demonstrating distinct differences in morphology based on the substrates properties. In general, CE cells appeared to have a more polygonal morphology, continuous ZO-1 at the cell-cell border and cortical F-actin on substrates with an elastic modulus of $50 \mathrm{kPa}$ for most of the ECM proteins. Similar results were observed for the COL4 coating for most of the elastic modulus formulations. Thus, the combination of elastic modulus and ECM protein that gave the best results in terms of the CE cell morphology most closely resembling that observed in vivo was an elastic modulus of $50 \mathrm{kPa}$ and COL4 coating, which was selected for further cell expansion studies.

substrate could maintain differentiated CE cells in a normal phenotype while enhancing proliferation during long-term culture. To test this we compared four different substrate conditions; TCPS as a standard control, TCPS coated with collagen type IV (TCPS COL4 $_{\text {) }}$ to evaluate the effect of the ECM protein coating, PDMS with elastic modulus of $50 \mathrm{kPa}$ but no protein to evaluate the effect of substrate stiffness $\left(\mathrm{PDMS}_{50}\right)$ and $\mathrm{PDMS}_{50+\mathrm{COL} 4}$. Long-term culture was performed for up to 10 passages, with the primary harvested $\mathrm{CE}$ cells seeded directly on and contacting only the specific substrate indicated (see Supplementary Fig. S2 online). The same number of CE cells was seeded onto each substrate at P0 and then split $1: 3$ at each subsequent passage. We did not control for cell density after P0 because we wanted to determine on which substrate CE cells could most rapidly expand using standard serial passaging techniques. From the outset, CE cells cultured on $\mathrm{PDMS}_{50}$ grew very slowly and failed to reach confluence by day 30 , thus this condition was not further evaluated (data not shown). Representative phasecontrast images (Fig. 3a) show that CE cell morphology and cell density varied substantially from P1 to P10 for cells on TCPS, $\mathrm{TCPS}_{\mathrm{COL} 4}$, and $\mathrm{PDMS}_{50+\mathrm{COL} 4}$. Qualitatively, CE cells at P1 on all three substrates exhibited a normal polygonal morphology; however, cells on TCPS were larger than those on TCPS COL4 $_{4}$ and PDMS $_{50+\text { COL4 }}$. By P5, CE cells on TCPS and TCPS adopted an enlarged and polarized morphology and at P8 were even further enlarged with irregular shapes, enlarged nuclei, and fibroblast-like morphology. In distinct contrast, $\mathrm{CE}$ cells on $\mathrm{PDMS}_{50+\mathrm{COL} 4}$ at P5 and P8 maintained a higher cell density and a polygonal morphology characteristic of CE cells. At P10, CE cells on all the substrates had lost their characteristic polygonal morphology, suggesting that even on the biomimetic substrate there is a limit to how long CE cell phenotype can be maintained over extended passages in vitro.

We next used image analysis to quantify CE cell density, growth rate and average cell size as a function of substrate condition and passage number. CE cell density (Fig. 3b, see statistical analysis in Supplementary Table S1 online) was normalized relative to the cell density on TCPS at P0 on a per harvest basis. At all passages CE cells on $\mathrm{PDMS}_{50+\mathrm{COL} 4}$ were at significantly greater density $(\sim 50 \%)$ than on TCPS, demonstrating that the biomimetic substrate improved proliferation. It is important to note that $\mathrm{TCPS}_{\mathrm{COL} 4}$ had cell densities in between that of $\mathrm{PDMS}_{50+\mathrm{COL} 4}$ and TCPS, suggesting that the ECM protein had some effect. However, this effect decreased over time, with cell denisty on $\mathrm{PDMS}_{50+\mathrm{COL} 4}$ greater than on both TCPS and TCPS $\mathrm{COL}_{4}$ from $\mathrm{P} 4$ through P10. Plotting cell proliferation as a function of time showed that CE cells on the PDMS ${ }_{50+C O L 4}$ had a $>3,000$-fold increase in cell number while maintaining a polgonal morphology up to P8 (Fig. 3c). This was more than an order-ofmagnitude greater than the increase in cell number on TCPS and 

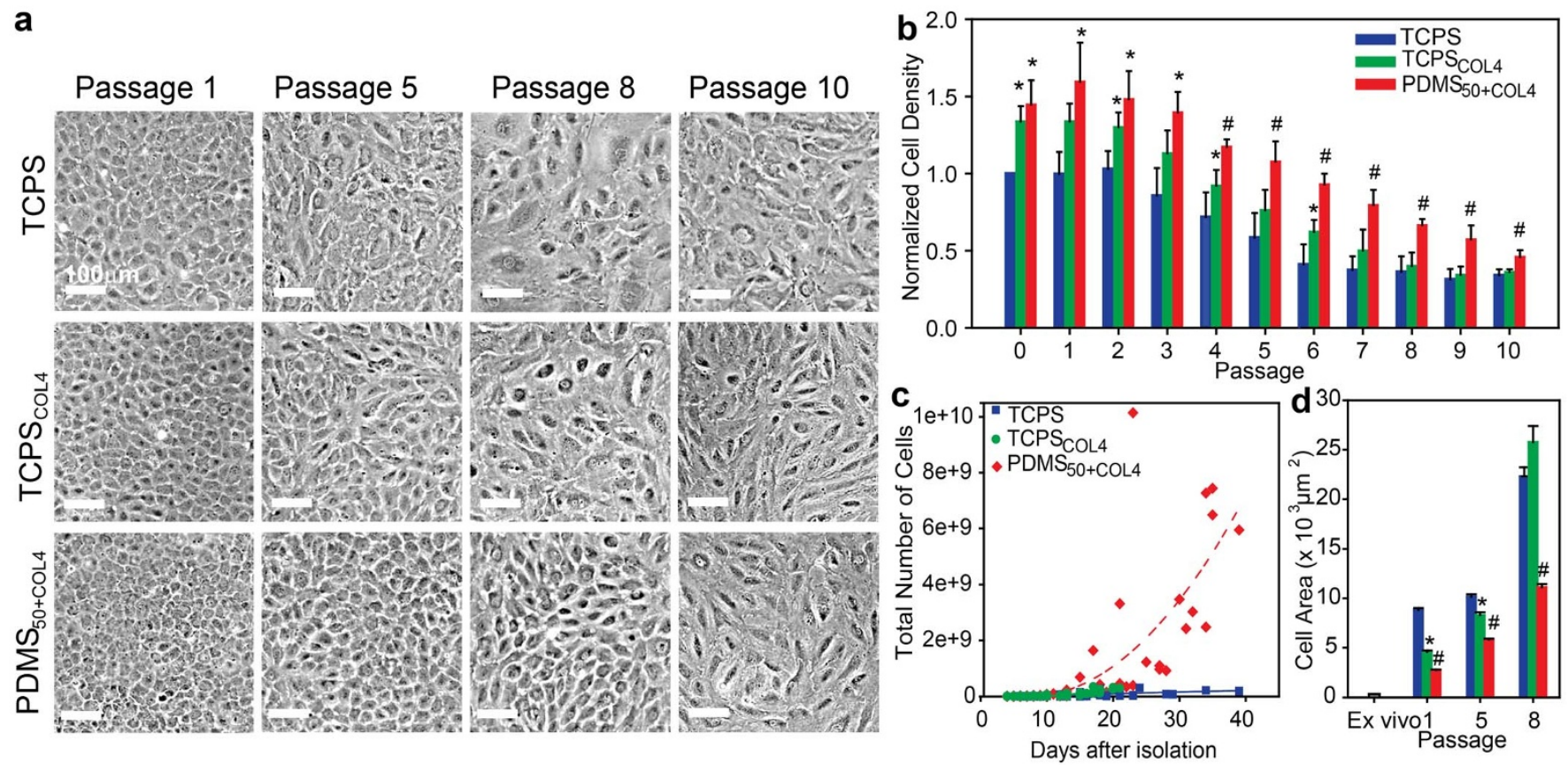

Figure $3 \mid$ CE cells cultured on the biomimetic PDMS 50+CoL4 $_{5}$ substrate maintained a polygonal morphology, higher cell density, increased proliferation rate and smaller cell size. (a) Representative phase contrast images showing the morphology of CE cells cultured on the three different substrates at four different passages. At P5, CE cells cultured on TCPS $\mathrm{COL} 4_{4}$ and TCPS exhibited elongated, irregular cell morphology. By P8 the cells were enlarged and polarized with no resemblance to a hexagonal morphology. In contrast, CE cells cultured on PDMS $\mathrm{S}_{50+\mathrm{COL}_{4}}$ maintained a hexagonal like morphology up to P8. (b) Normalized cell density for CE cells cultured on TCPS ( $\mathrm{n}=4)$, $\operatorname{TCPS}_{\mathrm{COL} 4}(\mathrm{n}=5)$ and PDMS $\mathrm{P}_{50+\mathrm{COL} 4}(\mathrm{n}=5)(\mathrm{mean} \pm$ s.d.). At all passages the density of CE cells on the PDMS $50+$ COL4 was significantly greater than on the TCPS and than on the TCPS COL4 $_{4}$ from P4 to P10.

(c) Number of CE cells on the different substrates as a function of time, where each data point represents cell number prior to passaging (up to P5 for TCPS and TCPS $\mathrm{COL} 4_{4}$ and P8 for PDMS ${ }_{50+\mathrm{COL} 4}$, when CE morphology became non-polygonal). There was a $>3000$-fold increase in the total cell number

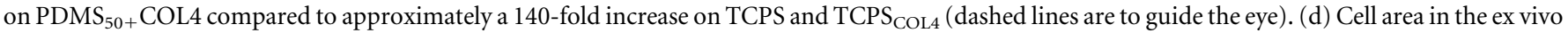
endothelium and on TCPS, TCPS $\mathrm{COL} 4_{4}$ and $\mathrm{PDMS}_{50+\mathrm{COL} 4}$ at P1, P5 and P8 (mean \pm s.e.m.). ( $\left.{ }^{*}\right)$ indicating a statistically significant difference $(\mathrm{P}<0.05)$ between PDMS $50+$ COL4 and TCPS and $(\#)$ indicating a statistically significant difference $(\mathrm{P}<0.05)$ between PDMS $_{50+C O L 4}$ and both TCPS and $\mathrm{TCPS}_{\mathrm{COL} 4}$.

TCPS $_{\text {COL4 }}$, which expanded only 139- and 138-fold respectively, and had already adopted a polarized morphology prior to P5 (Fig. 3c). Finally, we quanitifed average cell size at confluence on the different substrates as a function of passage number (Fig. 3d, see statistical analysis in Supplementary Table S2 online). While CE cell size was larger than that observed in the intract endothelium on all substrates, the CE cells cultured on the $\mathrm{PDMS}_{50+\mathrm{COL} 4}$ were smallest in size relative to TCPS and TCPS $\mathrm{COL}_{4}$ at all passages. In total, these results demonstrate that the $\mathrm{PDMS}_{50+\mathrm{COL} 4}$ substrate supported higher cell densities, greater proliferation rates and smaller cell size relative to the TCPS control and TCPS $\mathrm{COL} 4_{\text {substrates. }}$

CE Cell Phenotype is Maintained on the Biomimetic PDMS Substrate. Having established that the $\mathrm{PDMS}_{50+\mathrm{COL} 4}$ substrate enhanced proliferation, we next investigated whether $\mathrm{CE}$ phenotype was maintained. The phase-contrast images (Fig. 3a) suggested that the $\mathrm{CE}$ cells on $\mathrm{PDMS}_{50+\mathrm{COL} 4}$ remained differentiated with normal morphology, but to confirm this we stained for a variety of specific protein markers. The tight junction protein $\mathrm{ZO}-1$ revealed that on the biomimetic $\mathrm{PDMS}_{50+\mathrm{COL} 4}$ substrate $\mathrm{CE}$ junctional integrity was maintained at P1 and P5 with near continuous staining at the cell-cell borders (Fig. 4a), similar to that observed in the intact endothelium (Fig. 1a). On TCPS, little contiguous ZO-1 staining was observed in any of the cultures (Fig. 4a). Addition of collagen IV to TCPS did have an apparent effect, enabling some ZO-1 junctions to form at P1; however, by P5 the staining showed discontinuous regions (Fig. 4a). These results demonstrate that $\mathrm{PDMS}_{50+\mathrm{COL} 4}$ allows the $\mathrm{CE}$ cells to maintain continuous areas of tight junctions, and do so over an increased number of population doublings as compared to rigid TCPS controls.

The ability to maintain differentiated CE cells longer in culture on the $\mathrm{PDMS}_{50+\mathrm{COL} 4}$ suggested that the substrate was able to inhibit dedifferentiation or transformation relative to TCPS and TCPS ${ }_{\text {COL4 }}$. For example, after corneal damage CE cells in vivo can undergo EMT, becoming motile, fibroblastic, and forming a fibrous retrocorneal membrane containing the proteins fibronectin, collagen I, $\alpha$-smooth muscle actin, and vimentin. A similar EMT-like transformation occurs to CE cells in vitro in response to serum and growth factors $^{45}$. To understand why EMT appeared to be reduced for CE cells on the $\mathrm{PDMS}_{50+\mathrm{COL} 4}$ substrate, we first examined the ECM proteins being assembled at the cell/substrate interface. Collagen type IV was stained using antibodies, and was present up to P8 on the $\mathrm{PDMS}_{50+\mathrm{COL} 4}$ and TCPS $\mathrm{COL}_{4}$ pre-coated with the protein, but absent on the uncoated TCPS control (data not shown). This provided little insight, and simply indicated that the collagen type IV remained at the interface when pre-coated. Next, we stained for fibronectin, which is assembled by cells into fibrils and is characteristic of CE cells undergoing EMT in vivo ${ }^{46}$. By P1 CE cells on TCPS had organized the fibronectin into a fibrillar ECM network that became more pronounced by P5 (Fig. 4a). CE cells on TCPS COL4 $_{4}$ also assembled a fibrillar fibronectin matrix, though the effect was less pronounced with fibrils appearing shorter and less organized. In contrast, fibronectin assembled by $\mathrm{CE}$ cells on $\mathrm{PDMS}_{50+\mathrm{COL} 4}$ remained diffuse and at most developed into small, punctate-like fibrils (Fig. 4a). This lack of fibronectin fibrillar matrix formation indicated a distinct difference in how $\mathrm{CE}$ cells on the $\mathrm{PDMS}_{50+\mathrm{COL} 4}$ were behaving in terms of matrix assembly. 
a
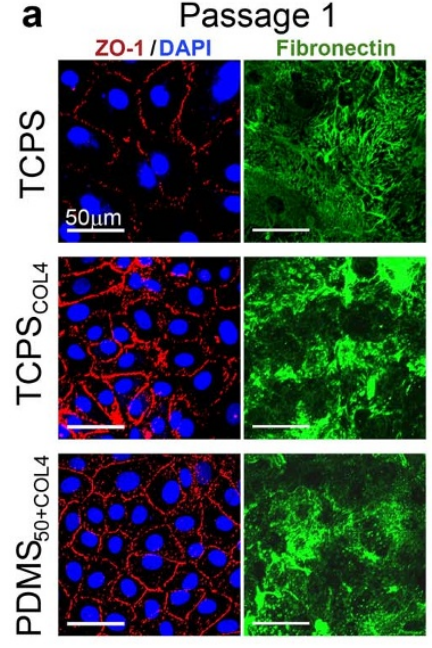

Passage 5
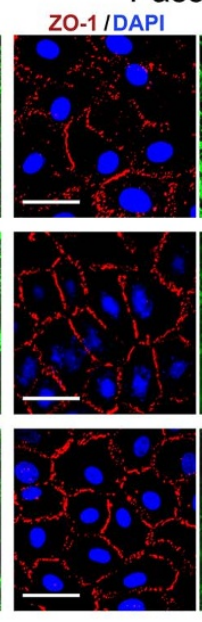
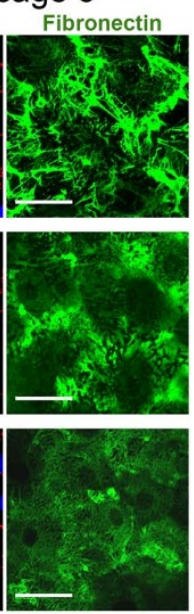
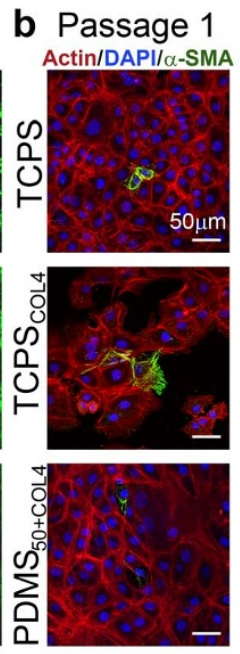

Passage 5
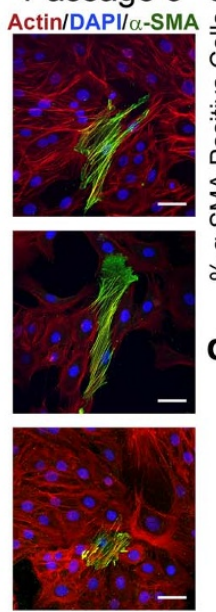

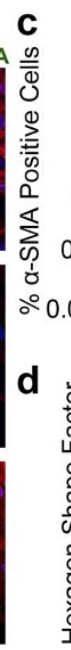

nature.com/scientificreports

Figure $4 \mid$ CE cells cultured on PDMS $_{50+C O L 4}$ maintained phenotypic ZO-1 staining and hexagonal shape while inhibiting fibronectin fibril formation and $\boldsymbol{\alpha}$-SMA expression. (a) Representative images of CE cells on TCPS, TCPS $\mathrm{COL} 4_{4}$ and PDMS $50+\mathrm{COL} 4$ stained for nuclei (blue) and ZO-1 (red) to show cell morphology and separate images stained for fibronectin (green) to show fibril assembly at the cell-substrate interface at P1 and P5. CE cells on $\mathrm{PDMS}_{50+\mathrm{COL} 4}$ had more continuous ZO-1 staining at the cell-cell border and decreased fibronectin fibril formation relative to cell on TCPS and

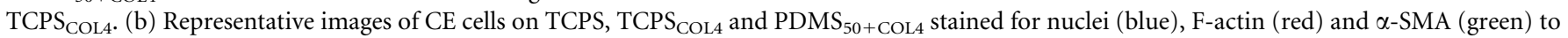
show cells that have undergone EMT to a fibroblast-like phenotype at P1 and P5. (c) Percentage of $\alpha$-SMA positive cells at P1 and P5 showing the increase in EMT on TCPS and TCPS COL4 $_{4}$ relative to $\mathrm{PDMS}_{50+\mathrm{COL} 4}$ (mean \pm s.d., ${ }^{*}$ indicates statistically significant difference relative to $\mathrm{PDMS} \mathrm{S}_{50+\mathrm{COL} 4}, \mathrm{P}<0.05$ ). (d) Hexagon shape factor (HSF) of CE cells in ex vivo, intact endothelium and at P1and P5 TCPS, TCPS $\mathrm{COL} 4_{4}$ and PDMS P0+COL4 (mean \pm s.e.m., * indicates TCPS $\mathrm{COL} 4_{4}$ had a statistically significant difference to TCPS and $\mathrm{PDMS}_{50+\mathrm{COL} 4}, \mathrm{P}<0.05$, and \# indicates PDMS $50+$ COL4 had a statistically significant difference to TCPS and TCPS $\mathrm{COL} 4, \mathrm{P}<0.05)$.

We next looked at the cytoskeleton and cell shape to further analyze differential cell responses. CE cells undergoing EMT are known to assemble robust actin cytoskeletons that are positive for $\alpha$-smooth muscle actin $(\alpha-S M A)^{47-51}$. At P1 CE cells on the three substrates exhibited very little $\alpha$-SMA by immunofluorescent staining (Fig. $4 \mathrm{~b}$ ). However, by P5, CE cells on the TCPS and the TCPS ${ }_{\mathrm{COL} 4}$ had more frequent $\alpha$-SMA positive cells, which appeared to be larger and had robust actin filament staining across the cell bodies (Fig. 4b). Quantification of the percent $\alpha$-SMA positive cells (Fig. 4c) revealed that even at P1 a significantly greater number of cells on TCPS expressed this protein compared to $\mathrm{PDMS}_{50+\mathrm{COL} 4}$. By P5 the per-

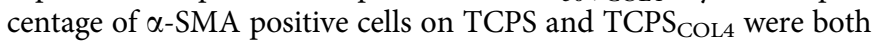
greater than $\mathrm{PDMS}_{50+\mathrm{COL} 4}$ (Fig. 4c, see statistical analysis in Supplementary Table S3 online). It should be noted that even though the percentage of $\alpha$-SMA positive cells on TCPS was only $\sim 1 \%$, this was still two orders-of-magnitude greater than on $\mathrm{PDMS}_{50+\mathrm{COL} 4}$. Finally, we used morphometric image analysis to determine whether the polygonal CE cells were able to reform a hexagonal morphology, similar to that observed in the intact endothelium (as seen in Fig. 1a). Here again results showed that $\mathrm{CE}$ cells on $\mathrm{PDMS}_{50+\mathrm{COL} 4}$ had a hexagon shape factor (HSF) that more closely matched that of CE cells in the intact endothelium in the ex vivo tissue (Fig. $4 \mathrm{~d}$, see statistical analysis in Supplementary Table S4 online). The HSF for CE cells on PDMS S0+COL4 $_{50}$ was significantly lower than on both TCPS and TCPS COL4 $_{\text {at }}$ P1 and P5. This result, in combination with the increased ZO-1 staining and decreased fibronectin fibrillar matrix formation strongly suggests that $\mathrm{CE}$ cells on the $\mathrm{PDMS}_{50+\mathrm{COL} 4}$ have more well-developed cell-cell interactions as compared to CE cells on TCPS and TCPS ${ }_{\text {COL4 }}$.

CE Cells Expanded on the Biomimetic PDMS Substrate form Higher Density Engineered Tissues. The ability to expand CE cells on the $\mathrm{PDMS}_{50+\mathrm{COL} 4}$ substrate provides the opportunity to generate large quantities of cells for therapeutic applications. As a first step to evaluate this potential, we tested the ability of the expanded CE cells to tissue engineer a corneal endothelium using a carrier substrate suitable for implantation. To do this we first

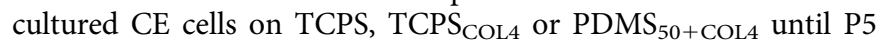
and then seeded 300,000 CE cells onto each $15 \mu \mathrm{m}$ thick, $20 \mathrm{~mm}$ diameter collagen type I gel, to approximate the corneal stroma. After 24 hours in culture it was observed that CE cells expanded on $\mathrm{PDMS}_{50+\mathrm{COL} 4}$ and then cultured on the collagen gel were growing at a higher density and were nearly confluent with a polygonal morphology. In contrast, CE cells expanded on TCPS and TCPS $_{\text {COL4 }}$ and then cultured on the collagen gel were subconfluent and had a polarized morphology (Fig. 5a). After 48 hours in culture, immunofluorescent labeling revealed that $\mathrm{CE}$ cells expanded on all three substrates were confluent, but those initially expanded on TCPS and TCPS COL $4_{4}$ had decreased ZO-1 at the cell-cell border and frequent actin filaments that traversed the cell body (Fig. 5a). In contrast, CE cells expanded on $\mathrm{PDMS}_{50+\mathrm{COL} 4}$ had many regions where ZO-1 was continuously stained at the cell-cell border along with actin filaments localized primarily to the cell periphery. CE cells expanded on $\mathrm{PDMS}_{50+\mathrm{COL} 4}$ also formed a significantly higher density monolayer $\left(1528 \pm 143\right.$ cells $\left./ \mathrm{mm}^{2}\right)$ compared to those formed by cells expanded on TCPS (921 \pm $\left.157 \mathrm{cells} / \mathrm{mm}^{2}\right)$ and $\mathrm{TCPS}_{\mathrm{COL} 4}\left(1122 \pm 168 \mathrm{cells} / \mathrm{mm}^{2}\right)$ (Fig. 5b, see statistical analysis in Supplementary Table S5 online). These results demonstrate that $\mathrm{CE}$ cells expanded on the $\mathrm{PDMS}_{50+\mathrm{COL} 4}$ have the potential to form an endothelium with $40 \%-50 \%$ higher density than CE cells expanded on the TCPS and TCPS COL4 $_{4}$ surfaces, establishing that the culture history of these cells is import even when the cells are subsequently seeded on a collagen type I gel scaffold.

\section{Discussion}

Our results demonstrate that the biomimetic PDMS substrate we developed enables CE cells to be expanded $>3,000$-fold in vitro while maintaining a range of phenotypic markers characteristic of differentiated endothelium. This is more than an order-of-magnitude increase in the cell expansion as compared to the TCPS and 

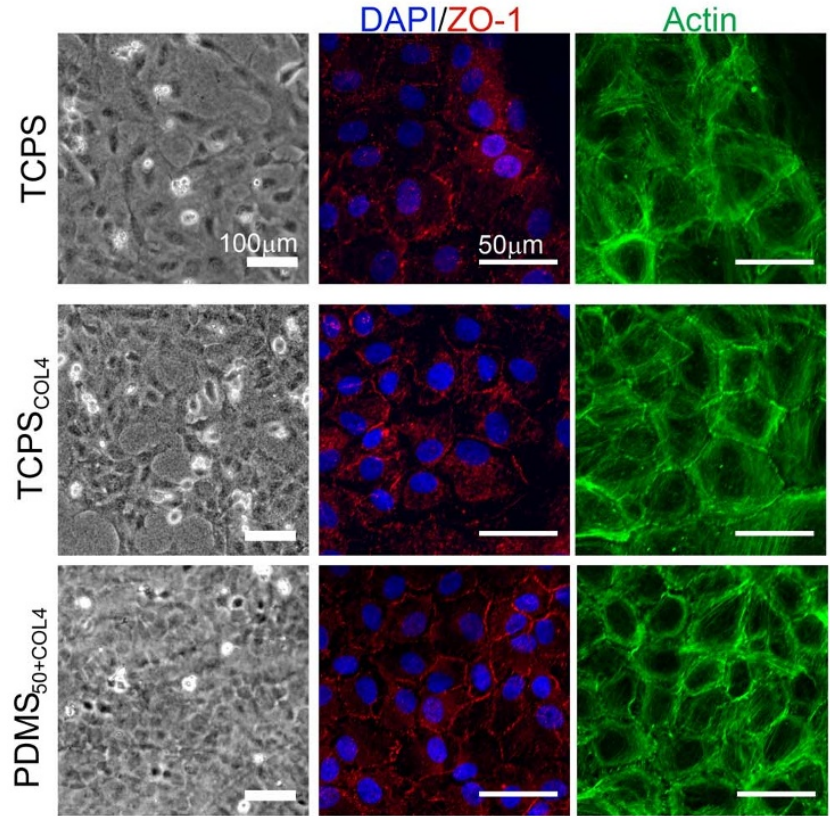

b

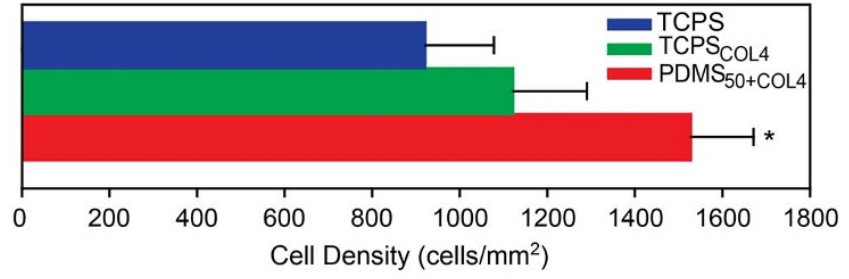

Figure 5 | CE cells expanded on $\mathrm{PDMS}_{50+\mathrm{COL} 4}$ formed a higher density, tissue engineered endothelium. (a) Representative phase contrast images and fluorescent confocal images of CE cells expanded on TCPS, TCPS $\mathrm{COL}_{4}$ and PDMS $\mathrm{P}_{50+\mathrm{COL} 4}$ until P5 and then seeded onto collagen type I gels to form a tissue engineered endothelium. CE cells expanded on $\mathrm{PDMS}_{50+\mathrm{COL} 4}$ formed a complete monolayer more rapidly and had a polygonal morphology by 24 hours. At 48 hours CE cells stained for nuclei (blue), $\mathrm{ZO}-1$ (red) and F-actin (green) appeared to have more continuous ZO-1 staining at the cell-cell border when expanded first on

$\mathrm{PDMS}_{50+\mathrm{COL4}}$. (b) Quantification of cell density in the tissue engineered endothelium showed that $\mathrm{CE}$ cells expanded on $\mathrm{PDMS}_{50+\mathrm{COL} 4}$ formed higher density monolayers (mean \pm s.d., $*$ indicates $\mathrm{PDMS}_{50+\mathrm{COL} 4}$ had a statistically significant difference compared to TCPS and TCPS $\mathrm{COL}_{4}, \mathrm{P}<$ $0.05)$.

$\mathrm{TCPS}_{\mathrm{COL} 4}$, and other quantitative metrics including cell density, cell size, $\alpha$-SMA expression and HSF were also all improved on the $\mathrm{PDMS}_{50+\mathrm{COL} 4}$. While we used a 36 -condition screen to identify the $\mathrm{PDMS}_{50+\mathrm{COL} 4}$ substrate, it turns out that the combination of an elastic modulus of $50 \mathrm{kPa}$ and collagen type IV coating is similar to the native Descemet's membrane upon which CE cells adhere to in vivo $^{43,44}$. While in hindsight it might seem obvious that mimicking Descemet's membrane would work, the body of literature to date has described a broad range of soluble and insoluble molecules used to improve the culture of CE cells. For example, CE cells have been expanded with varying degrees of success on surface immobilized collagen type $\mathrm{I}^{34}$, collagen type $\mathrm{IV}^{34}$, laminin ${ }^{33,34}, \mathrm{FNC}^{1,18,34}$, and fibronectin ${ }^{32,34}$. Other approaches have focused on soluble factors added to culture media such as bFGF, EGF and $\mathrm{NGF}^{20}$, the addition of extracts from bovine corneal endothelial cells ${ }^{21}$, ROCK inhibitor Y $27632^{22-24}$, ascorbic acid 2 phosphate ${ }^{25,26}$ and TGF- $\beta$ inhibitor SB $431542^{52}$; the use viral transfections ${ }^{30,31}$ or reprogramming of the cells to neural crest progenitor cells ${ }^{17,53,54}$. For example, Zhu et al showed that knockdown of p120 Catenin and Kaiso promoted an $\sim 15$-fold expansion of human CE cells while maintaining a cell density of $>2,000$ cells $/ \mathrm{mm}^{253}$. What is unique about our approach is the incorporation of substrate mechanics as an additional factor, which in combination with the collagen type IV coating provides a simple system to expand CE cells that relies solely on microenvironmental factors, i.e. mechanical and biochemical properties of the substrate, in order to induce cell proliferation. This allows us to use a very minimal media containing only the basal DMEM media, serum and antibiotics without the need for additional growth factors, small molecules or genetic alterations to the CE cells during expansion.

The primary question raised by our results is why the PDMS $_{50+\mathrm{COL} 4}$ achieved improved results compared to the TCPS and TCPS $\mathrm{COL} 4_{4}$ controls. The data clearly shows that relatively speak-

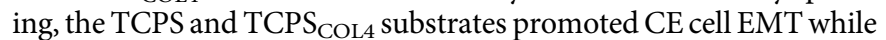
the $\mathrm{PDMS}_{50+\mathrm{COL} 4}$ substrate inhibited it. This assessment is supported by the fact that CE cells cultured on $\mathrm{PDMS}_{50+\mathrm{COL} 4}$ had significantly smaller cell areas and HSF as compared to controls and more robust ZO-1 staining and cortical actin at all time points. This apparent increase in cell-cell adhesion and lack of spreading on $\mathrm{PDMS}_{50+\mathrm{COL} 4}$ is important, because EMT is characterized by cell polarization and loss of the polygonal morphology, which is inhibited when cells are in a densely packed monolayer ${ }^{45}$. There are a wide range of markers for EMT including the morphological markers already mentioned as well as expression of transcription factors such as Snail, Slug and Twist ${ }^{50}$. Here we selected expression of $\alpha$-SMA in the cytoskeleton throughout the cell as a definitive marker of EMT in endothelial cells that have transformed into fibroblasts. The CE cells expressing $\alpha$-SMA were readily identified by their robust expression, and at P5 $\alpha$-SMA positive cells had actin stress fibers throughout the cells, especially noticeable on the TCPS (P1 and P5) and TCPS COL4 $_{4}$ (Fig. $4 \mathrm{~b}$ ). The percentage of $\alpha$-SMA positive CE cells on TCPS (P1 and P5) and $\mathrm{TCPS}_{\mathrm{COL} 4}$ (P5) was significantly greater than on $\mathrm{PDMS}_{50+\mathrm{COL} 4}$ (Fig. 4c), confirming relative inhibition of EMT on the biomimetic substrate. The expression of $\alpha$-SMA is considered a relatively mature marker of EMT, and thus it is likely that a larger percentage of CE cells have progressed to some intermediate state of EMT $^{50}$. The fact that the CE cells on TCPS ${ }_{\mathrm{COL} 4}$ are different by most metrics compared to $\mathrm{PDMS}_{50+\mathrm{COL} 4}$ indicates that the collagen type IV coating is not solely responsible for the inhibition of EMT. Rather, the data suggests that the difference is also due to the lower elastic modulus of the $\mathrm{PDMS}_{50+\mathrm{COL} 4}$. Imaging of the fibronectin matrix assembled by CE cells on the different substrates revealed that the soft $\mathrm{PDMS}_{50+\mathrm{COL} 4}$ had a pronounced effect by preventing large fibril formation (Fig. 4a). It is known that substrates with elastic modulus in the 10's of kiloPascal range inhibit stress fiber and focal adhesion formation relative to stiffer substrates ${ }^{36,37}$, and that stress fibers and the resulting cell contractility increase fibronectin matrix assembly $^{55}$. Further, recent reports have demonstrated that integrinmediated TGF $\beta$ activation and EMT is increased on stiff fibronectin coated surfaces as compared to softer surfaces due to the increased cell contractility ${ }^{56}$. This provides an explanation for why the $\mathrm{PDMS}_{50+\mathrm{COL} 4}$ is better at inhibiting EMT relative to the controls, that the soft $\mathrm{PDMS}_{50+\mathrm{COL} 4}$ inhibits actin stress fiber formation, which limits contractility and fibronectin fibrillar matrix assembly, and which in turn reduces integrin-mediated TGF $\beta$ activation and EMT.

The variable quality of corneal donor tissue and the limited availability of donor corneas outside the US highlight the need to develop a tissue engineered endothelium suitable for implantation. Many studies use one donor cornea to create one tissue engineered $\mathrm{CE}$, which does not address the need for an increase in the availability of CE monolayers for transplant. The $\mathrm{PDMS}_{50+\mathrm{COL} 4}$ developed here is a potential solution to this problem, providing a substrate on which to expand enough CE cells to engineer multiple tissues from a single 
donor. To evaluate whether this is possible, we performed proof-ofconcept experiments using a thin, collagen type I gel as a substrate for engineering a freestanding endothelium. Results showed that P5 cells expanded on $\mathrm{PDMS}_{50+\mathrm{COL} 4}$ could form a dense monolayer with polygonal cells that expressed ZO-1 at the cell-cell borders and cortical F-actin. The CE cell density on the $\mathrm{PDMS}_{50+\mathrm{COL} 4}$ was higher than on the controls, which is important because this should improve the pump function of the tissue. While we did not implant this tissue in this study to test function in vivo, the results do show that CE cells expanded on $\mathrm{PDMS}_{50+\mathrm{COL} 4}$ generate a larger total number of cells and that they form higher density monolayers with improved expression of phenotypic markers. For implantation we would also want to further increase CE cell density to $>1,500$ cells $/ \mathrm{mm}^{2}$, which should be achievable by increasing cell seeding density. Future work will examine whether the biomimetic $\mathrm{PDMS}_{50+\mathrm{COL} 4}$ validated here using bovine CE cells is also effective for expanding human CE cells. Note that we used bovine cells in these experiments because they provided a consistent and reproducible source of cells for the 36condition substrate screen and expansion studies. Bovine corneas are larger than human and we could obtain 25-50 age matched 1-2 yearold eyes at one time to get the number of cells required. Further, we will also investigate whether there is a synergistic effect by combining the PDMS $\mathrm{P}_{50+\mathrm{COL} 4}$ surface with soluble factors such as ROCK inhibitor, Y-27632 24 and TGF- $\beta$ inhibitor, SB $431542^{52}$, which have also been shown to increase the proliferative capacity of CE cells in vitro. Finally, we plan to test the engineered corneal endothelium on the collagen type I gel carrier (Fig. 5) in an in vivo animal model in order to determine whether the pump function is maintained in the expanded cells. Studies with human CE cells will be far more challenging due to limited supply and cost of donor tissue, donor to donor variability, the small number of CE cells that can be recovered from each cornea and the potential need to further optimize the biomimetic PDMS substrate for species-specific differences.

\section{Methods}

CE Cell Isolation and Culture. Bovine CE cells were isolated from fresh whole bovine eyes (Pel-Freez Biologicals, Rogers AR, USA). The corneas were excised from whole globes and soaked for 20 minutes in PBS containing 1\% penicillin/streptomycin/ amphotericin B and $0.5 \%$ gentamicin. Corneas were incubated endothelial side up in a 12-well spot plate with approximately $300 \mu \mathrm{L}$ of TrypLE Express at $37^{\circ} \mathrm{C}$ for 20 minutes. CE cells were released into the TrypLE Express by gently scraping with a rubber scalpel, combined and centrifuged for 5 minutes at $1500 \mathrm{rpm}$. The cells were designated as passage 0 (P0), resuspended in low glucose DMEM with $10 \%$ FBS, $1 \%$ penicillin/streptomycin/amphotericin $\mathrm{B}$ and $0.5 \%$ gentamicin and cultured in standard TCPS flasks or flasks coated with PDMS and/or collagen type IV depending on the experiment.

Screening of Substrate Biochemical and Mechanical Properties. To perform the substrate screen we used six different elastic modulus PDMS formulations, which were prepared according to previously published methods ${ }^{42}$. Briefly, Sylgard 184 PDMS elastomer and Sylgard 527 PDMS gel were prepared separately according to the manufacturer's specifications. Sylgard $184(E=1720 \mathrm{kPa})$ was prepared by mixing 10 parts base with 1 part curing agent $(10: 1)$ for 2 minutes at 2,000 RPM in a Thinky Cup Conditioning mixer followed by a defoaming cycle of 2 minutes at 2000 RPM. Sylgard $527(E=5 \mathrm{kPa})$ was prepared by mixing equal weights of part A and part B (1:1) for 2 minutes at 2,000 RPM followed by defoaming at 2000 RPM for two minutes. The intermediate elastic modulus PDMS formulations were prepared by mixing Sylgard 184 and Sylgard 527 in defined mass ratios of $5: 1(E=1.34 \mathrm{MPa})$, $1: 1(E=830 \mathrm{kPa}), 1: 5(E=130 \mathrm{kPa})$, and $1: 10(E=50 \mathrm{kPa})$. For these PDMS blends, the Sylgard 184 and 527 were weighed and combined together using an additional mixing and defoaming cycle. All six PDMS formulations were spin coated onto $25 \mathrm{~mm}$ diameter glass coverslips at 4,000 RPM to create $\sim 15 \mu \mathrm{m}$ thick films followed by curing at $60^{\circ} \mathrm{C}$ for 8 hours. Coverslips were treated in a UV-Ozone cleaner for 15 minutes and used as-is or coated with either $50 \mu \mathrm{g} / \mathrm{mL} \mathrm{FN}$ (human plasma, BD Biosciences, San Jose, CA, USA), $100 \mu \mathrm{g} / \mathrm{mL}$ collagen type I (rat tail Sigma-Aldrich CO, St. Louis, MO, USA)., $50 \mu \mathrm{g} / \mathrm{mL}$ laminin (Engelbreth-HolmSwarm mouse tumor, BD Biosciences), $50 \mu \mathrm{g} / \mathrm{mL}$ collagen type IV (human placenta, Sigma-Aldrich), a mixture of $50 \mu \mathrm{g} / \mathrm{mL}$ laminin or $50 \mu \mathrm{g} / \mathrm{mL}$ collagen type IV in distilled deionized water for one hour at room temperature. Uncoated controls and ECM protein coated samples were rinsed three times in phosphate buffered saline (PBS) before cell culture experiments. Coverslips were seeded with 300,000 bovine CE cells (P2) and monitored for cell growth and morphology over a 7 day period using phase contrast microscopy. On day 7 , all samples were fixed, stained and imaged using confocal microscopy.
Long-term Culture and Expansion of CE Cells. The four different substrates used in the expansion experiments were TCPS, TCPS $\mathrm{COL}_{4}, \mathrm{PDMS}_{50}$ and $\mathrm{PDMS}_{50+\mathrm{COL} 4}$. To prepare TCPS $_{\mathrm{COL} 4}$, a T-25 flask was coated with $5 \mathrm{~mL}$ of $50 \mu \mathrm{g} / \mathrm{mL}$ collagen type IV for one hour at room temperature, rinsed once and stored with $5 \mathrm{~mL}$ of ddH $\mathrm{H}_{2} \mathrm{O}$ inside until use. The $\mathrm{PDMS}_{50}$ was prepared by coating T-25 flasks with a $\sim 0.5 \mathrm{~mm}$ thick layer of the $50 \mathrm{kPa}$ elastic modulus PDMS formulation and cured at $60^{\circ} \mathrm{C}$ for 24 hours

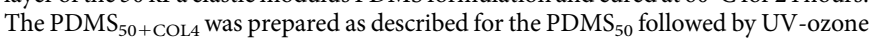
treatment and coated with collagen type IV as described for the TCPS COL4 $_{\text {. All flasks }}$ were used within 3 days of protein coating. Bovine CE cells from 30-50 corneas were isolated as described above, pooled, and seeded evenly on to the four substrates described above (note: 10 corneas per surface to be seeded were used in each trial). CE cells were cultured until confluent and serial passaged $1: 3$ until passage 10 . Briefly, at each passage the confluent cells from each substrate were released using TrypLE Express, centrifuged and resuspended in $6 \mathrm{~mL}$ of culture media. Next, $2 \mathrm{~mL}$ of the cell suspension was seeded in to a new flask, $2 \mathrm{~mL}$ was frozen and the final $2 \mathrm{~mL}$ was seeded onto $\mathrm{PDMS}_{50+\mathrm{COL} 4}$ coated coverslips or TCPS controls for staining and imaging. Four trials were performed from separate cell isolations resulting in TCPS (n $=4), \operatorname{TCPS}_{\mathrm{COL} 4}(\mathrm{n}=5)$ and $\mathrm{PDMS}_{50+\mathrm{COL} 4}(\mathrm{n}=5)$ flasks (all trials had at least one flask of each type, the final trial had two each of the TCPS $\mathrm{COL} 4_{4}$ and PDMS $\mathrm{P}_{50+\mathrm{COL} 4}$ flasks). CE cells seeded onto PDMS ${ }_{50}$ at $\mathrm{P} 0$ failed to reach confluence after 30 days and therefore were not used in further experiments. Cell morphology and confluence were monitored daily using a Nikon TS100 phase contrast microscope equipped with a Nikon D7000 camera. Cell density at confluence was calculated using the phase contrast images and the multi-point selection tool in ImageJ. To enable direct comparison of the different cell isolations (where the number of cells and cell viability can vary), cell density was normalized to the TCPS cell density at P0 at confluence for each trial. The substrates were statistically compared at each passage using the Shapiro-Wilk normality test and one-way ANOVA ( $\alpha$ set to 0.050 ) with Bonferroni post-hoc test (SigmaPlot Systat Software Inc.). The total number of cells at each passage was an estimate, calculated by assuming that each flask was split into 3 new flasks at each passage (though as noted only 1 flask was maintained).

Immunofluorescent Staining and Image Analysis. Cover slips used for the substrate screen were fixed and permeabilized in PBS containing $4 \%$ paraformaldehyde and $0.05 \%$ of Triton X-100 for 10 minutes. After fixation, samples were incubated with $1: 200$ dilution of DAPI (Life Technologies) and $1: 100$ dilutions of monoclonal mouse anti-ZO-1 (Life Technologies) and Alexa Fluor 633 conjugated phalloidin (Life Technologies) in PBS for 2 hours at $37^{\circ} \mathrm{C}$. Samples were rinsed 3 times in PBS and incubated with $1: 100$ dilution of Alexa Fluor 555 goat anti-mouse secondary antibody for two hours at $37^{\circ} \mathrm{C}$. Samples were rinsed 3 times in PBS and mounted using Pro-Long gold anti-fade reagent. Confocal microscopy was performed on a Zeiss LSM 700 confocal microscope. Samples used for the long-term expansion were fixed at P1 and P5 and then permeabilized and stained using one of two different protocols. To visualize fibronectin, samples were stained for the nucleus (DAPI) and ZO-1 as described for the cover slips with the addition of a $1: 100$ dilution of polyclonal rabbit anti-FN (Sigma-Aldrich) with goat anti-rabbit Alexa Fluor 488 secondary antibody. To visualize $\alpha$-SMA, samples were stained for the nucleus (DAPI) and F-actin (phalloidin) as described for the cover slips with the addition of a $1: 100$ dilution of monoclonal mouse anti- $\alpha$-SMA (Abcam, MA) with goat antimouse Alexa Fluor 488 secondary antibody. Samples were mounted using Pro-Long gold anti-fade reagent and imaged on a Zeiss LSM 700 laser scanning confocal microscope.

Quantitative image analysis was performed using a combination of ImageJ and Metamorph software. The percentage of cells expressing $\alpha$-SMA was determined by using the multi-point selection tool in ImageJ to count the number of $\alpha$-SMA positive cells and reporting this as a percentage relative to the total number of cells based on DAPI stained nuclei. Results for the three substrates were statistically analyzed at P1 and P5 using one-way ANOVA on the ranks with Tukey's pairwise comparison (SigmaPlot). The hexagonal shape factor (HSF) was calculated using quantitative morphology analysis of the ZO-1 at the cell-cell border and DAPI nuclear staining to verify the presence of the cells in each location. Metamorph (Molecular Devices) was used to detect the ZO-1 fluorescence and create a rendering of the outline of each cell in an image followed by manual touchup. From these outlines Metamorph calculated the cell area $(\mathrm{A})$, perimeter $(\mathrm{P})$ and $\mathrm{HSF}=\left(\mathrm{P}^{2} / \mathrm{A}\right)-13.856$ for each cell ${ }^{57,58}$. Results for CE cells on the three substrates were statistically analyzed at P1 and P5 using a one-way ANOVA on the ranks with Dunn's pairwise comparison (SigmaPlot).

Tissue Engineered CE Monolayers. Collagen type I gels were fabricated by pipetting $200 \mu \mathrm{L}$ of a $6 \mathrm{mg} / \mathrm{mL}$ collagen I solution (rat tail, BD Biosciences) onto a glass coverslip with a $20 \mathrm{~mm}$ diameter adhesive silicon ring used to control the shape of the gel. The gels were then placed in a $37^{\circ} \mathrm{C}, 5 \% \mathrm{CO}_{2}$ incubator for 3 hours to evaporate excess water ${ }^{59}$. The gels were then removed and completely dried in a biohood before rehydrating in PBS and sterilization by UV treatment for 15 minutes. CE cells at P5 from each of the three substrates were seeded onto the collagen I gels at a density of 300,000 cells per gel, with 3 gels per condition. Cells were monitored for cell growth and morphology over a 48 hour day period using phase contrast microscopy. At 48 hours, all samples were fixed and permeabilized in PBS containing $4 \%$ paraformaldehyde and $0.05 \%$ of Triton X-100 for 10 minutes and stained for the nucleus (Nuc Blue, Life Technologies), ZO-1 and F-actin as described above. The cell density was calculated by counting the cells in the fluorescent images. Statistical analysis was performed using a one-way ANOVA ( $\alpha$ set to 0.050 ) with Tukey pairwise comparison test to determine statistical significance. 
1. Zhu, C. \& Joyce, N. C. Proliferative response of corneal endothelial cells from young and older donors. Invest Ophth Vis Sci. 45, 1743-1751 (2004).

2. Joyce, N. C. Proliferative capacity of the corneal endothelium. Prog Retin Eye Res. 22, 359-389 (2003)

3. Joyce, N. C., Meklir, B., Joyce, S. J. \& Zieske, J. D. Cell cycle protein expression and proliferative status in human corneal cells. Invest Ophth Vis Sci. 37, 645-655 (1996).

4. Joyce, N. C., Navon, S. E., Roy, S. \& Zieske, J. D. Expression of cell cycle-associated proteins in human and rabbit corneal endothelium in situ. Invest Ophth Vis Sci. 37, 1566-1575 (1996).

5. Murphy, C., Alvarado, J., Juster, R. \& Maglio, M. Prenatal and Postnatal Cellularity of the Human Corneal Endothelium - a Quantitative Histologic-Study. Invest Ophth Vis Sci. 25, 312-322 (1984).

6. Nucci, P., Brancato, R., Mets, M. B. \& Shevell, S. K. Normal endothelial cell density range in childhood. Arch Ophthalmol. 108, 247-248 (1990).

7. Engelmann, K., Bednarz, J. \& Valtink, M. Prospects for endothelial transplantation. Exp Eye Res. 78, 573-578 (2004).

8. Price, M. O. \& Price, F. W., Jr. Descemet membrane endothelial keratoplasty. Int Ophthalmol Clin. 50, 137-147 (2010).

9. Terry, M. A. \& Ousley, P. J. Deep lamellar endothelial keratoplasty in the first United States patients: early clinical results. Cornea. 20, 239-243 (2001).

10. Terry, M. A. \& Ousley, P. J. Endothelial replacement without surface corneal incisions or sutures: topography of the deep lamellar endothelial keratoplasty procedure. Cornea. 20, 14-18 (2001).

11. Melles, G. R., Lander, F., van Dooren, B. T., Pels, E. \& Beekhuis, W. H. Preliminary clinical results of posterior lamellar keratoplasty through a sclerocorneal pocket incision. Ophthalmology. 107, 1850-1856; discussion 1857 (2000).

12. Faraj, L. A., Hashmani, K., Khatib, T., Al-Aqaba, M. \& Dua, H. S. The changing face of corneal graft rejection. Br. J. Ophthalmol. 96, 1049-1050 (2012).

13. Wu, E. I., Ritterband, D. C., Yu, G., Shields, R. A. \& Seedor, J. A. Graft rejection following descemet stripping automated endothelial keratoplasty: features, risk factors, and outcomes. Am. J. Ophthalmol. 153, 949-957 e941 (2012).

14. Price, M. O. et al. Descemet's Stripping Automated Endothelial Keratoplasty Three-Year Graft and Endothelial Cell Survival Compared with Penetrating Keratoplasty. Ophthalmology. 120, 246-251 (2013).

15. Peh, G. S. L., Beuerman, R. W., Colman, A., Tan, D. T. \& Mehta, J. S. Human Corneal Endothelial Cell Expansion for Corneal Endothelium Transplantation: An Overview. Transplantation. 91, 811-819 (2011).

16. Tan, D. T. H., Dart, J. K. G., Holland, E. J. \& Kinoshita, S. Ophthalmology 3 Corneal transplantation. Lancet. 379, 1749-1761 (2012).

17. Zhu, Y. T., Chen, H. C., Chen, S. Y. \& Tseng, S. C. G. Nuclear p120 catenin unlocks mitotic block of contact-inhibited human corneal endothelial monolayers without disrupting adherent junctions. J. Cell Sci. 125, 3636-3648 (2012).

18. Peh, G. S. L., Toh, K. P., Wu, F. Y., Tan, D. T. \& Mehta, J. S. Cultivation of Human Corneal Endothelial Cells Isolated from Paired Donor Corneas. PLoS ONE. 6 (2011)

19. Peh, G. S. et al. Propagation of Human Corneal Endothelial Cells? A Novel Dual Media Approach. Cell Transplant. DOI: 10.3727/096368913X675719 (2013).

20. Chen, K. H., Azar, D. \& Joyce, N. C. Transplantation of adult human corneal endothelium ex vivo: a morphologic study. Cornea 20, 731-737 (2001).

21. Gao, Y. et al. In vitro culture of human fetal corneal endothelial cells. Graef Arch Clin Exp. 249, 663-669 (2011).

22. Okumura, N. et al. Enhancement of corneal endothelium wound healing by Rhoassociated kinase (ROCK) inhibitor eye drops. Br J Ophthalmol. 95, 1006-1009 (2011).

23. Okumura, N. et al. Enhancement on primate corneal endothelial cell survival in vitro by a ROCK inhibitor. Invest Ophth Vis Sci. 50, 3680-3687 (2009).

24. Okumura, N. et al. ROCK Inhibitor Converts Corneal Endothelial Cells into a Phenotype Capable of Regenerating In Vivo Endothelial Tissue. Am J Pathol. 181, 268-277 (2012).

25. Kimoto, M., Shima, N., Yamaguchi, M., Amano, S. \& Yamagami, S. Role of hepatocyte growth factor in promoting the growth of human corneal endothelial cells stimulated by L-ascorbic acid 2-phosphate. Invest Ophth Vis Sci. 53, 7583-7589 (2012).

26. Shima, N., Kimoto, M., Yamaguchi, M. \& Yamagami, S. Increased proliferation and replicative lifespan of isolated human corneal endothelial cells with Lascorbic acid 2-phosphate. Invest Ophth Vis Sci. 52, 8711-8717 (2011).

27. Miyata, K. et al. Effect of donor age on morphologic variation of cultured human corneal endothelial cells. Cornea. 20, 59-63 (2001).

28. Baum, J. L., Niedra, R., Davis, C. \& Yue, B. Y. J. T. Mass-Culture of Human Corneal Endothelial-Cells. Arch Ophthalmol-Chic. 97, 1136-1140 (1979).

29. Yue, B. Y. J. T., Sugar, J., Gilboy, J. E. \& Elvart, J. L. Growth of Human Corneal Endothelial-Cells in Culture. Invest Ophth Vis Sci. 30, 248-253 (1989)

30. Bednarz, J., Aboalchamat, B. \& Engelmann, K. Characterization of immortalized human corneal endothelial cells. Invest Ophth Vis Sci. 41, S448-S448 (2000).

31. Bednarz, J., Teifel, M., Friedl, P. \& Engelmann, K. Immortalization of human corneal endothelial cells using electroporation protocol optimized for human corneal endothelial and human retinal pigment epithelial cells. Acta Ophthalmol Scand. 78, 130-136 (2000).

32. Blake, D. A., Yu, H. N., Young, D. L. \& Caldwell, D. R. Matrix stimulates the proliferation of human corneal endothelial cells in culture. Invest Ophth Vis Sci. 38, 1119-1129 (1997).
33. Yamaguchi, M. et al. Adhesion, migration, and proliferation of cultured human corneal endothelial cells by laminin-5. Invest Ophth Vis Sci. 52, 679-684 (2011)

34. Choi, J. S. et al. In vitro evaluation of the interactions between human corneal endothelial cells and extracellular matrix proteins. Biomed Mater. 8 (2013).

35. Engler, A. J. et al. Embryonic cardiomyocytes beat best on a matrix with heart-like elasticity: scar-like rigidity inhibits beating. J. Cell Sci. 121, 3794-3802 (2008)

36. Engler, A. J., Sen, S., Sweeney, H. L. \& Discher, D. E. Matrix elasticity directs stem cell lineage specification. Cell 126, 677-689 (2006).

37. Pelham, R. J., Jr. \& Wang, Y. Cell locomotion and focal adhesions are regulated by substrate flexibility. Proc Natl Acad Sci U S A. 94, 13661-13665 (1997)

38. Pelham, R. J., Jr. \& Wang, Y. L. Cell locomotion and focal adhesions are regulated by the mechanical properties of the substrate. Biol Bull. 194, 348-349; discussion 349-350 (1998)

39. Koizumi, N. et al. Cultivated corneal endothelial cell sheet transplantation in a primate model. Invest Ophth Vis Sci. 48, 4519-4526 (2007).

40. Proulx, S. et al. Tissue engineering of feline corneal endothelium using a devitalized human cornea as carrier. Tissue Eng Part A. 15, 1709-1718 (2009).

41. Proulx, S. et al. Transplantation of a tissue-engineered corneal endothelium reconstructed on a devitalized carrier in the feline model. Invest Ophth Vis Sci.50, 2686-2694 (2009).

42. Palchesko, R. N., Zhang, L., Sun, Y. \& Feinberg, A. W. Development of Polydimethylsiloxane Substrates with Tunable Elastic Modulus to Study Cell Mechanobiology in Muscle and Nerve. PLoS ONE. 7, e51499 (2012).

43. Kabosova, A. et al. Compositional differences between infant and adult human corneal basement membranes. Invest Ophth Vis Sci. 48, 4989-4999 (2007).

44. Last, J. A., Liliensiek, S. J., Nealey, P. F. \& Murphy, C. J. Determining the mechanical properties of human corneal basement membranes with atomic force microscopy. J. Struct Biol. 167, 19-24 (2009).

45. Lee, J. G., Ko, M. K. \& Kay, E. P. Endothelial mesenchymal transformation mediated by IL-1beta-induced FGF-2 in corneal endothelial cells. Exp Eye Res. 95, 35-39 (2012).

46. Kawaguchi, R. et al. Extracellular matrix components in a case of retrocorneal membrane associated with syphilitic interstitial keratitis. Cornea. 20, 100-103 (2001).

47. Chen, Q. K., Lee, K., Radisky, D. C. \& Nelson, C. M. Extracellular matrix proteins regulate epithelial-mesenchymal transition in mammary epithelial cells. Differentiation. 86, 126-132 (2013).

48. Kalluri, R. \& Weinberg, R. A. The basics of epithelial-mesenchymal transition. J. Clin Invest. 119, 1420-1428 (2009).

49. Scanlon, C. S., Van Tubergen, E. A., Inglehart, R. C. \& D’Silva, N. J. Biomarkers of epithelial-mesenchymal transition in squamous cell carcinoma. J. Dent Res. 92, 114-121 (2013)

50. Zeisberg, M. \& Neilson, E. G. Biomarkers for epithelial-mesenchymal transitions. J. Clin Invest. 119, 1429-1437 (2009).

51. Ishizaki, M., Zhu, G., Haseba, T., Shafer, S. S. \& Kao, W. W. Expression of collagen I, smooth muscle alpha-actin, and vimentin during the healing of alkali-burned and lacerated corneas. Invest Ophth Vis Sci. 34, 3320-3328 (1993).

52. Okumura, N. et al. Inhibition of TGF-beta Signaling Enables Human Cornea Endothelial Cell Expansion In Vitro for Use in Regenerative Medicine. PLoS ONE 8 (2013).

53. Zhu, Y. T. et al. Knockdown of Both p120 Catenin and Kaiso Promotes Expansion of Human Corneal Endothelial Monolayers via RhoA-ROCK-Noncanonical BMP-NF kappa B Pathway. Invest Ophth Vis Sci. 55, 1509-1518 (2014).

54. Li, W. et al. A novel method of isolation, preservation, and expansion of human corneal endothelial cells. Invest Ophth Vis Sci. 48, 614-620 (2007).

55. Halliday, N. L. \& Tomasek, J. J. Mechanical properties of the extracellular matrix influence fibronectin fibril assembly in vitro. Exp Cell Res. 217, 109-117 (1995).

56. Brown, A. C., Fiore, V. F., Sulchek, T. A. \& Barker, T. H. Physical and chemical microenvironmental cues orthogonally control the degree and duration of fibrosis-associated epithelial-to-mesenchymal transitions. J. Patho.l 229, 25-35 (2013).

57. Behndig, A. Corneal endothelial integrity in aging mice lacking superoxide dismutase-1 and/or superoxide dismutase-3. Mol Vis. 14, 2025-2030 (2008).

58. Behndig, A., Karlsson, K., Brannstrom, T., Sentman, M. L. \& Marklund, S. L. Corneal endothelial integrity in mice lacking extracellular superoxide dismutase. Invest Ophth Vis Sci. 42, 2784-2788 (2001).

59. Brown, R. A., Wiseman, M., Chuo, C. B., Cheema, U. \& Nazhat, S. N. Ultrarapid engineering of biomimetic materials and tissues: Fabrication of nano- and microstructures by plastic compression. Adv Funct Mater. 15, 1762-1770 (2005).

\section{Acknowledgments}

This work was supported by an Ocular Tissue Engineering and Regenerative Medicine in the Ophthalmology (OTERO) postdoctoral fellowship from the Louis J. Fox Center for Vision Restoration at UPMC to R.N.P., the National Institutes of Health (NIH) Director's New Innovator Award Program, grant number DP2HL117750 to A.W.F., and NIH CORE Grant P30 EY008098, the Eye and Ear Foundation of Pittsburgh, PA, and Unrestricted Grant from Research to Prevent Blindness to the Univ of Pittsburgh, Dept of Ophthalmology. 


\section{Author contributions}

R.N.P. conducted experiments and analyzed data. K.L.L. analyzed data. R.N.P., J.L.F. and A.W.F. designed the experiments and wrote the manuscript.

\section{Additional information}

Supplementary information accompanies this paper at http://www.nature.com/ scientificreports

Competing financial interests: Yes, there is potential competing interest. Drs. Palchesko, Funderburgh and Feinberg are co-inventors on a filed patent application related to the expansion technology in this manuscript.
How to cite this article: Palchesko, R.N., Lathrop, K.L., Funderburgh, J.L. \& Feinberg, A.W. In Vitro Expansion of Corneal Endothelial Cells on Biomimetic Substrates. Sci. Rep. 5, 7955; DOI:10.1038/srep07955 (2015).

(c) (1) (2) This work is licensed under a Creative Commons Attribution-NonCommercialShareAlike 4.0 International License. The images or other third party material in this article are included in the article's Creative Commons license, unless indicated otherwise in the credit line; if the material is not included under the Creative Commons license, users will need to obtain permission from the license holder in order to reproduce the material. To view a copy of this license, visit http:// creativecommons.org/licenses/by-nc-sa/4.0/ 